\title{
PENGARUH SPESIFIKASI TUGAS, POLA KOORDINASI, DAN MOTIVASI TERHADAP KINERJA PEGAAI DI LINGKUNGAN KANTOR KECAMATAN KARTASURA (Studi Kasus: Kantor Kecamatan Kartasura, Kabupaten Sukoharjo)
}

\author{
Rakaditya Nugraha, Supawi Pawenang, Sarsono \\ Fakultas Ekonomi Manajemen Universitas Islam Batik Surakarta \\ Email:nugraharaka51@gmail.com
}

\begin{abstract}
This study a medito analyze the impactoof job spesification, coordination pattern and motivation on employee performance. The sample was the employee of the Kantor Kecamatan Kartasura totaling 35 respondents. Regression analysis technique were use to analyze the impact of job spesification, coordination pattern, and motivation of the employee performance is by using SPSS. The analysis showed that the job spesification have significant positive effect on employee performance. The analysis also showed that coordination pattern significant influence on employee performance. And motivation significant positive influence on employee performance.The contribution ofpthe three independent variables on employee performance is $76,2 \%$.
\end{abstract}

Keywords: job specification, coordination pattern, motivation

\section{PENDAHULUAN}

Pemerintahan Indonesia saat ini sedang melaksanakan proses pengembangan, perbaikan, perubahan, dan pembangunan sistem pemerintahan secara meyeluruh. Salah satunya adalah di bidang sistem pemerintahan yang terdapat di dalamnya, hal ini bisa dimulai dari sistem pemerintahan di tingkat atas hingga sistem pemerintahan di tingkat yang paling bawah. Dalam melaksanakan suatu pekerjaan setiap individu harus memiliki spesifikasi tugas, pola atau jalur koordinasi, dan juga motivasi kerja yang tinggi. Oleh karena itu, spesifikasi tugas haruslah dijelaskan serta ditegaskan dan juga dilaksanakan sesuai dengan tugas dan fungsinya. Dengan harapan bahwa siapapun yang memerlukan jasa mereka akan terpuaskan dengan layanan yang mereka berikan. Dalam hal ini akan dibicarakan studi kasus di Kantor Kecamatan Kartasura, Kabupaten Sukoharjo terhadap kinerja pegawainya mengenai spesifikasi tugas, pola koordinasi, dan motivasinya.

Menurut Pattisahusiwa, Salmah (2013) mengatakan bahwa jabatan-jabtan yang ada dalam organisasi pemerintahan pada umumnya dikelompokkan dalam dua golongan besar, yaitu jabatan structural yang bobot tugas pekerjaan bersifat manajerial, dan jabatani fungsional yang bersifat non manajerial. Hal ini berarti bahwa profesionalime di lingkungan aparatur pemerintahan dapat dikembangkan melalui spesifikasi jabatan. Dengan kata lain spesifikasi jabatan dalam pengelolaan sumber daya aparatur menjadi penting dalam oganisasi. Sumber daya aparatur dalam potensi manusiawi sebagai penggerak organisasi dalam mewujudkan ekisistensinya. Dalam perkembanganya, organisasi akan menghadapi berbagai permasalahan sumber daya aparatur yang kompleks. Oleh karena itu diperlukan adanya suatu system pengelolaan yang menangani sumber daya aparatur atau dengan kata lain manajemen sumber daya aparatur. Salah satunya kegiatan dalam manajemen sumber daya aparatur yang memiliki peran yang sangat penting dalam membentuk profesionalisme aparatur dan kinerja organisasi adalah spesifikasi tugas. 
Analisis jabatan merupakan prosedur untuk menetapkan tugas dan tuntunan keterampilan dari suatu jabatan/pekerjan (job description) dan orang macam apa yang akan melaksanakan pekerjaan tersebut atau (job Specification). Pengertian ini, pada dasarnya menekankan pada dua aspek, yaitu menyangkut isi pekerjaan dan orang yang melaksanakan pekerjaan. Dengan kata lain bahwa spesifikasi merupakan bagian dari proses-proses administrasi maupun manajemen sumber daya aparatur dalam meni ngkatkan kinerja pegawai. Menurut Darmanto, Fadjar Rohmat (2018) mengatakan bahwa koordinasi adalah proses pengintegrasian tujuan-tujuan dan kegiatan-kegiatan pada satuan yang terpisah (antar departemen atau bidang-bidang fungsional) pada suatu organisasi untuk mencapai tujuan secara efisien dan efektif, serta menggerakkan tim dengan memberikan lokasi kegiatan pekerjaan yang cocok kepada masing-masing dan menjaga agar kegiatan itu dilaksanakan dengan keselarasan yang semestinya di antara para anggota itu sendiri. Menurut Potu, Aurelia (2013) motivasi merupakan faktor yang paling menentukan bagi seseorang pegawai dalam bekerja. Motivasi merupakan respon karyawan terhadap sejumlah pernyataan mengenai keseluruhan usaha yang timbul dari dalam diri pegawai agar tumbuh dorongan untuk bekerja dan tujuan yang dikehendakinya dapat tercapai. Lingkungan kerja merupakan segala sesuatu yang ada di sekitar pegawai pada saat bekerja, baik yang berupa fisik aannya saat bekerja. Lingkungan kerja yang memuaskan bagi pegawai dapat meningkatkan kinerja sebaliknya lingkungan kerja yang tidak memadai akan dapat menurunkan kinerja dan akhirnya menurunkan motivasi kerja pegawai.

Kantor Kecamatan Kartasura Kabupaten Sukoharjo adalah salah suatu lembaga pemerintahan yang berfungsi sebagai administrarif kecamatan secara struktural, mempunyai fungsi yang sangat strategis dan penting bagi masyarakat. Di dalam pengurusan administrasi layanan umum seperti KTP, KK, Surat Pindah, Surat Pengantar Nikah, dan lain-lain. Masyarakat umumnya hanya perlu melakukanya sampai pada tingkat kecamatan. Dengan demikian, wilayah kecamatan menjadi kepengurusan administratif dan sekaligus membawahi banyak kelurahan di bawahnya, pegawainya akan mempunyai tugas dan beban kerja yang sangat tinggi dan intensitasnya dibandingkan ditingkat kelurahan.

Di Kecamatan Kartasura, Kabupaten Sukoharjo terdapat beberapa wilayah yang sebagian berbentuk kelurahan dan desa. Dalam hal ini wilayah desa dipimpin oleh kepala desa, sedangkan kelurahan dipimpin oleh lurah. Walaupun berbeda namun keduanya memiliki tanggung jawab yang terpusat dan terkoordinir pada suatu sisrtem pemerintahan yang berada di Kantor Kecamatan Kartasura, Kabupaten Sukoharjo.

Berdasarkan penelitian yang akan dilakukan, kami mengambil sampel kinerja pegawai pada Kantor Kecamatan Kartasura, Kabupaten Sukoharjo. Maka penulis melakukan penelitan dengan judul Pengaruh Spesifikasi Tugas, Pola Koordinasi, dan Motivasi Terhadap Kinerja Pegawai Di Lingkungan Kantor Kecamatan (Studi Kasus: Kantor Kecamatan Kartasura, Kabupaten Sukoharjo).

\section{LANDASAN TEORI}

\section{Kinerja Pegawai}

Octorano, Feronika Donny (2015) mengemukakan kinerja berasal dari kata Job Perfomance atau Actual Performance, merupakan hasil secara kualitas dan kuantitas yang di capai seorang pegawai dalam melaksanakan tugasnya sesuai dengan taggung jawab yang diberikan kepadanya. 


\section{Spesifikasi Tugas}

Job specification atau spesifikasi tugas menjelaskan syarat- syarat minimum yang harus dipenuhi oleh pekerjan untk melaksanakan pekerjaan-pekrjaan dalam jabatan tertentu. Secara sederhana job specification atau spesifikasi tugas menjelaskan sebuah jabatan Purwanti, Nisa Rita Rr., Firdaus, Aziz Muhammad., dan Rachmatullaily (2018).

\section{Pola Koordinasi}

Darmanto, Fadjar Rochmad (2018) koordinasi adalah suatu usaha kerja yang sama antara badan, instansi unit dalam pelaksanaan tugas-tugas tertentu, sehingga terhadap saling mengisi, saling membantu dan saling melengkapi.

\section{Motivasi}

Menurut Sahanggamu, M. Patricia., dan Mandley, L. Silvia (2014) bahwa motivasi merupakan pemberian daya penggerak yang menciptakan kegairahan kerja seseorng, agar mau bekerja sama, bekerja efektif dan terintegrasi dengan segala daya upayanya untuk mencapai kepuasan.

\section{Kerangka Pemikiran}

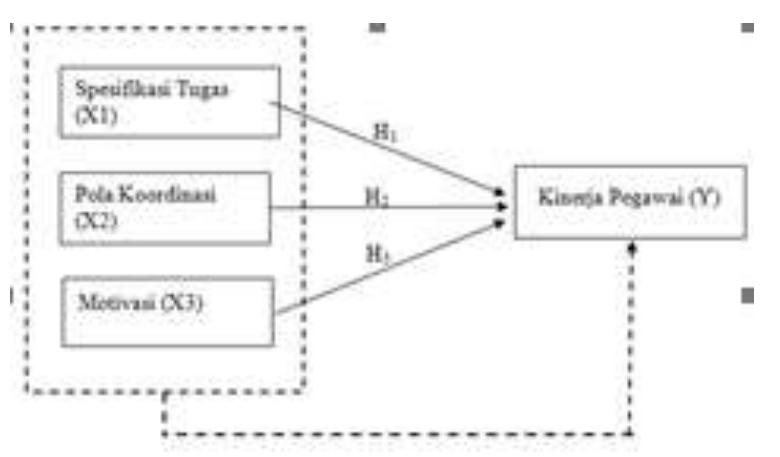

\section{Hipotesa}

1) Terdapat pengaruh positif dan signifikan antara spesifikasi tugas terhadap kinerja pegawai di kantori Kecamatan Kartasura, Kabupaten Sukoharjo.

2) Terdapat pengaruh positif dan signifikan antara Pola Koordinasi terhadap kinerja pegawai Kecamatan Kartasura, Kabupaten Sukoharjo.

3) Terdapat pengaruh positif dan signifikan antara Motivasi terhadap kinerja pegawai Kecamatan Kartasura, Kabupaten Sukoharjo.

4) Terdapat pengaruh spesifikasi tugas, pola koordinasi, dan motivasi secara simultan terhadap kinerja pegawai di kantor Kecamatan Kartasura, Kabupaten Sukoharjo.

\section{METODOLOGI PENELITIAN}

Jenis penelitian ini adalah penelitian kuantitatif, dengan menggunakan metode penelitian deskriptif dengan pendekatan survey yang bersumber dari data pegawai di kantor Kecamatan Kartasura, Kabupaten Sukoharjo . Penelitian berlokasi dikantor Kecamatan Karatasura, Kabupaten Sukoharjo, dengan alamat Jln. Adi Sumarmo No. 68, Kecamatan Kartasura Kabupaten Sukoharjo. Waktu penelitian dilakukani pada bulan November Desember 2019. Objek penelitian adalah di Kantor Kecamatan Kartasura, Kabupaten 
Sukoharjo. Populasi dalam penelitian ini adalah seluruh pegawai di kantor Kecamatan Kartasura, Kabupaten Sukoharjo yang berjumlah kurang lebih 35 karyawan. Sampel yang digunakan peneliti 35 pegawai.

\section{Hasil Uji Asumsi Klasik}

\section{Uji Normalitas Data}

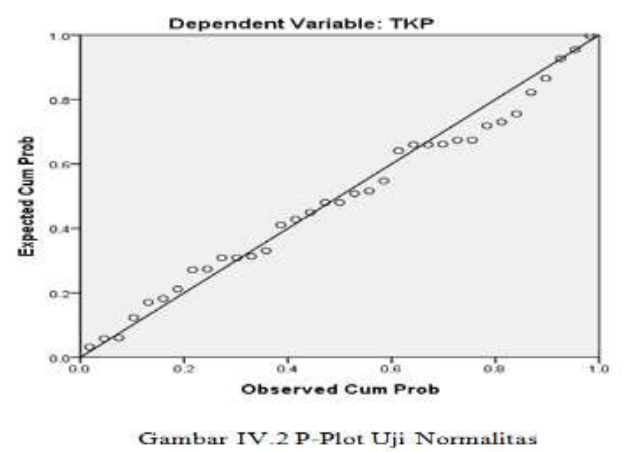

Pada gambar P-Plot terlihat titik- titik mengikuti dan mendekati garis diagonal sehingga dapat disimpulkan model regresi memenuhi asumsi normalitas.

\section{Uji Multikolinearitas}

Tabel IV.11

Hasil Uji Multikolinearitas

\begin{tabular}{|c|c|c|c|}
\hline \multirow[t]{2}{*}{ Model } & \multicolumn{2}{|c|}{ Collinearity Statistics } & \multirow{2}{*}{ Keterangan } \\
\hline & Tolerance & $V I F$ & \\
\hline $\begin{array}{l}\text { Spesifikasi } \\
\text { Tugas }\end{array}$ & .563 & 1.776 & $\begin{array}{l}\text { Tidak terjadi } \\
\text { multikolinearitas }\end{array}$ \\
\hline $\begin{array}{l}\text { Pola } \\
\text { Koordinasi }\end{array}$ & .843 & 1.186 & $\begin{array}{l}\text { Tidak terjadi } \\
\text { multikolinearitas }\end{array}$ \\
\hline Motivasi & .552 & 1.811 & $\begin{array}{l}\text { Tidak terjadi } \\
\text { multikolinearitas }\end{array}$ \\
\hline
\end{tabular}

Sumber: Data yang diolah 2019

Hasil uji multikolonieritas dapat diketahui bahwa seluruh variabel independn memiliki nilai Tolerance lebih besar dari 0,10 dan nilai Variance Inflation Factor (VIF) lebih kecil dari 10 sehingga dapat disimpulkan bahwa model regresi pada penelitian ini tidak terjadi multikolonierits.

\section{Uji Heteroskedastisitas}

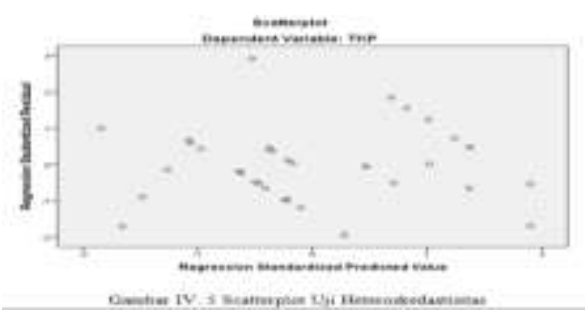


Berdasarkan output Scatterplots diatas diketahui bahwa titik-titik data menyebar diatas dan dibawah atau disekitar angka 0. Selain itu titik-titik tidak mengumpul hanya diatas atau dibawah dan penyebaran titik-titik tidak berpola. Dengan demikian dapat disimpulkan tidak terjadi masalah heteroskedastisitas sehingga model regresi baik dan ideal.

\section{Hasil Analisis Regresi Linear Berganda}

Tabel IV.12

Hasil Uji Analisis Regresi Linear Berganda

\begin{tabular}{|l|l|l|}
\hline Model & \multicolumn{2}{|l|}{ Unstandardrized Coefficient } \\
\hline & B & Std.Eror \\
\hline (Constant) & 6.427 & 1.582 \\
\hline Spesifikasi Tugas & .300 & .090 \\
\hline Pola Koordinasi & .196 & .059 \\
\hline Motivasi & .226 & .061 \\
\hline
\end{tabular}

Sumber: Data yang diolah 2019

a. Konstanta $=6,427$ artinya spesifikasi tugas, pola koordinasi, dan motivasi sebesar0 (nol) maka kinerja pegawai Kecamatan Kartasura akan sebesar 6,427.

b. Koefisien $\quad$ b1 $=0,300$ menunjukkan besarnya pengaruh spesifikasi tugas dengan nilai positif pada koefisien b1 menunjukkan apabila spesifikasi tugas naik satu satuan, sementara pola koordinasi dan motivasi konstan (nol), maka kinerja pegawai juga akan meningkatsebesar 0,300satuan.

c. Koefisien b2 $\quad$ b,196 menunjukkan besarnya pengaruh pola koordinasi dengan nilai positif pada koefisien b2 menunjukkan apabila pola koordinasi naik satu satuan, sementara spesifikasi tugas dan motivasi konstan (nol), maka kinerja pegawai juga akan meningkat sebesar 0,196 satuan.

d. Koefisien $\quad$ b3 $=0,226$ menunjukkan besarnya pengaruh motivasi dengan nilai positif pada koefisien b3 menunjukkan bahwa apabila motivasi naik satu satuan, sementara spesifikasi tugas dan pola koordinasi konstan (nol), maka kinerja pegawai juga akan meningkat sebesar 0,226 satuan.

\section{Hasil Uji F}

Tabel IV.13

Hasil Uji F

\begin{tabular}{|l|l|l|}
\hline Model & $\mathrm{F}_{\text {hitung }}$ & Sig \\
\cline { 1 - 1 } Regression & 37.244 & $.000^{\mathrm{b}}$ \\
\cline { 1 - 1 } Residual & & \\
\cline { 1 - 1 } Total & & \\
\hline
\end{tabular}

Sumber: Data yang diolah 2019 
Karena Fhitung $>$ Ftabel (34.244> 3,29), dan nilai sig 0,000 $<0,005$ maka Ho ditolak, berarti variabel spesifikasi tugas, pola koordinasi, dan motivasi secara bersama-sama atau simultan berpengaruh positif dan signifikan terhadap kinerja pegawai

\section{Hasil Uji t}

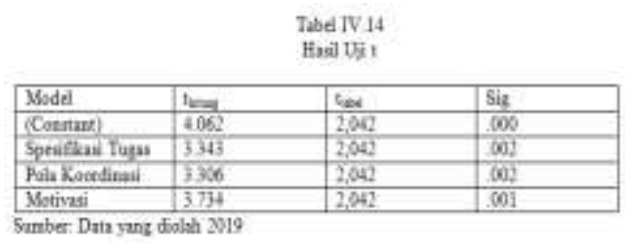

Variabel spesifikasi tugas diketahui thitung $(3,343)$ lebih besar daripada tabel $(2,042)$ dan nilai signifikansi $0,002<\alpha=0,05$ maka Ho ditolak, berarti variabel spesifikasi tugas berpengaruh positif dan signifikan terhadap kinerja pegawai.

\section{Hasil Uji Koefisien Determinasi $\left(\mathbf{R}^{2}\right)$}

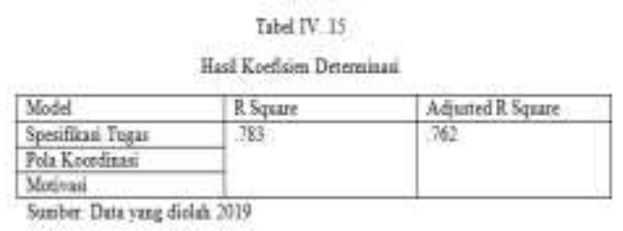

Hasil perhitungan nilai $\mathrm{R}^{2}$ diperoleh angka koefisien determinasi dengan adjusted $\mathrm{R}^{2}$ sebesar $76,2 \%$. Hal ini berarti bahwa variabel kinerja pegawai dapat dijelaskan oleh variabel spesifikasi tugas, pola koordinasi, motivasi sedangkan sisanya yaitu

$23,8 \%$ dijelaskan oleh faktor-faktor lain di luar model yang diteliti seperti loyalitas, beban kerja, dan lain-lain.

\section{Pembahasan}

1. Pengaruh Spesifikasi Tugas, Pola Koordinasi, Motivasi Terhadap Kinerja Pegawai Pada Kantor Kecamatan Kartasura, Kabupaten Sukoharjo.

Hasil Uji menunjukkan bahwa

secara simultan spesifikasi tugas, pola koordinasi, dan motivasi berpengaruh positif dan signifikan terhadap kinerja pegawai pada kantor kecamatan Kartasura, kabupaten Sukoharjo.

2. Pengaruh Spesifikasi Tugas Terhadap Kinerja Pegawai Berdasarkan hasil uji t hipotesis secara parsial pengaruh spesifikasi tugas terhadap kinerja karyawan di Kantor Kecamatan Kartasura, Kabupaten Sukoharjo diketahui memiliki nilai thitung $>$ tabel $(3,343>2,042)$ lebih besar dari tabel atau dapat dilihat dari nilai signifikansi $0,002<0,05$ maka Ho ditolak.

3. Pengaruh Pola Koordinasi Terhadap Kinerja Pegawai Berdaskan hasil uji t hipotesis secara parsial pengaruh pola koordinasi terhadap kinerja karyawan di kantor Kecamatan, Kabupaten Sukoharjo diketahui memiliki nilai thitung > tabel $(3,306>$ 2,042 ) lebih besar dari ttabel atau dapat dilihat dari nilai signifikansi $0,002<0,05$ maka Ho ditolak. 


\section{Pengaruh Motivasi Terhadap \\ Kinerja Pegawai}

Berdasarkan hasil uji $\mathrm{t}$

hipotesis secara parsial pengaruh motivasi terhadap kinerja pegawai di kantor Kecamatan Kartasura, Kabupaten Sukoharjo diketahui memiliki nilai thitung $<$ tabel $(3,734>2,042)$ lebih besar dari tabel atau dapat dilihat dari nilai signifikansi $0,001<0,05$ maka Ho ditolak.

\section{KESIMPULAN DAN SARAN}

\section{A. Kesimpulan}

Hasil uji F menunjukkan bahwa

spesifikasi tugas, pola koordinasi, motivasi secara simultan dan signifikan berpengaruh terhadap kinerja pegawai pada kantor Kecamatan Kartasura, Kabupaten Sukoharjo. Dari hasil uji t menunjukkan:

a. Variabel spesifikasi tugas berpengaruh positif dan signifikani terhadap kinerja pegawai pada kantor Kecamatann Kartasura, KabupatenoSukoharjo.

b. Variabel pola koordinasi berpengaruh positif dan signifikan terhadap kinerja pegawai pada kantor Kecamatan Kartasura, Kabupaten Sukoharjo.

c. Variabel motivasi berpengaruh positif dan signifikan terhadap kinerja pegawai pada kantor Kecamatan Kartasura, Kabupaten Sukoharjo.

\section{B. Saran}

1. Bagi Kantor Kecamatan

Kartasura, Kabupaten Sukoharjo sebaiknya Kantor Kecamatan Kartasura mempertahankan dan memanage spesifikasi tugas, pola koordinasi, motivasi menjadi lebih baik agar kinerja pegawai terus meningkat.

2. Peneliti Selanjutnya

Penelitian selanjutnya diharapkan dapat mengembangkan penelitian dengan metode lain dalam meneliti spesifikasi tugas, pola koordinasi, motivasi, dan kinerja pegawai.

Selain itu dapat menggunakan variabel lain untuk meneliti kinerja pegawai.

\section{DAFTAR PUSTAKA}

Darmanto, F.R., "Pengaruh Budaya, Disiplin Dan Koordinasi Terhadap Kinerja Karyawan PT Kereta Api Indonesia (PERSERO) DOAP 1 Jakrarta." Jurnal Pengembangan Wiraswasta, Vol. 20, No. 2 (2018).

Purwanti, N.R.Rr., Muhamad, A.F., Rachmatullaily., "Job Design Dan Job Specification Terhadap Produktivitas Pegawai.” Jurnal Ilmiah Inovator, Edisi September (2018).

Sahangggamu, M.P., Mandey, L.S., "Pengaruh Pelatihan Kerja, Motivasi, Dan Disiplin Kerja Terhadap Kinerja Karyawan Pada PT. Bank Perkreditan Rakyat Dana Raya.” Jurnal EMBA, Vol. 2, No. 4 (2014). 